\title{
Vaginal Infections in Pregnant Women at the Bè Hospital in Lomé (Togo) from 2008 to 2013
}

\author{
Koku A. Dakey ${ }^{*}$, Téou Alfa1, Yaovi A. Bossa ${ }^{1,2}$, Komlan Amevo3 , Amétépé Kpotsra1, \\ Yaovi Ameyapoh ${ }^{1}$
}

\author{
${ }^{1}$ Laboratory of Microbiology and Quality Control of Foodstuffs, School of Biological and Food Techniques, University of Lomé, \\ Lomé, Togo \\ ${ }^{2}$ Tsévié Regional Hospital, Tsévié, Togo \\ ${ }^{3}$ Bè Secondary Hospital, Lomé, Togo \\ Email: *richard.dakey@gmail.com
}

How to cite this paper: Dakey, K.A., Alfa, T., Bossa, Y.A., Amevo, K., Kpotsra, A. and Ameyapoh, Y. (2018) Vaginal Infections in Pregnant Women at the Bè Hospital in Lomé (Togo) from 2008 to 2013. Open Access Library Journal, 5: e4441.

https://doi.org/10.4236/oalib.1104441

Received: February 22, 2018

Accepted: March 23, 2018

Published: March 26, 2018

Copyright (C) 2018 by authors and Open Access Library Inc.

This work is licensed under the Creative Commons Attribution International License (CC BY 4.0).

http://creativecommons.org/licenses/by/4.0/

\section{Open Access}

\begin{abstract}
Sexually transmitted infections remain a public health problem almost all around the world. Women of childbearing age frequently have vulvovaginitis. The aim of this work is to evaluate the prevalence of the main germs responsible for vaginal infections in pregnant women who have had their vaginal swabs taken at Bè hospital. We conducted a retrospective study between May 2008 and December 2013, on 126 pregnant women in whom a vaginal swab was performed. We vaginally sampled 126 pregnant women, of whom 90 or $71.43 \%$ had vaginal infections. Candida albicans was the most frequently isolated species (47.97\%) followed by Gardnerella vaginalis (38.21\%). The most affected age group was between 25 and 30 years old. Candida albicans were respectively resistant to miconazole, clotrimazole and econazole. Our study showed that pregnant women are highly exposed to vaginal infections with a predominance of Candida albicans and Gardnerella vaginalis. This shows that it is necessary to do at least one culture of vaginal swabs during pregnancy for each woman.
\end{abstract}

\section{Subject Areas}

Microbiology

\section{Keywords}

Vaginal Infection, Bacterial Vaginosis, Vaginitis Infectious, Pregnancy, Togo

\section{Introduction}

The vaginal flora of healthy women is made up of a wide variety of anaerobic 
and aerobic bacteria. The most represented species is the kind Lactobacillus (Döderlein Bacillus) [1]. Lactobacilli are involved in maintaining the natural balance of the vaginal flora, and thus protect this flora. This role is especially important during pregnancy, because of vaginal abnormalities such as bacterial vaginosis and vaginitis infectious [2]. These abnormalities have been described as mechanisms responsible for premature births and perinatal complications [3].

We talk about bacterial vaginosis when the normal balance of bacteria in the vagina is disrupted and replaced by a proliferation of pathogenic bacteria. Lactobacilli are replaced by anaerobic microorganisms such as Gardnerella vaginalis and Mycoplasma hominis [4] [5]. Bacterial vaginosis is known to be a significant risk factor for adverse pregnancy outcomes [5].

Infectious vaginitis is defined as an infection related to a pathogen; it is also an abnormal manifestation of a bacterium, a parasite or a fungus that usually occurs in minute quantities. These are infections with Gardnerella [4], Neisseria gonorrhoeae, Trichomonas vaginalis [6] [7] [8] but also fungal infections. The fungi responsible for vaginitis are mainly caused by yeasts of the genus Candida; in this case we are talking about vaginal candidiasis.

We have superficial or local candidiasis and deep or visceral candidiasis. Superficial candidiasis comes when we have the passage of yeasts from the commensal state to the pathological state; deep candidiasis is defined by the involvement of at least one deep organ.

In Togo, a similar study was conducted in Sokodé in the central region in 2011 [9].

The main objective of our study was to determine the prevalence of vaginal infections in pregnant women in a secondary hospital in Lomé.

\section{Material and Methods}

This is a retrospective descriptive study carried out from the registers of the gynecological services and the registers of the microbiology laboratory of the Bè hospital. It covers a period of 5 years from May 2008 to December 2013. This hospital includes the services of gynecology-obstetrics, pediatrics, general medicine, ophthalmology, stomatology, radiology, social service, and laboratory of biology, service of maintenance, hygiene and vaccination. The inclusion criteria are all registrations of pregnant women who came to the laboratory during the study period and the non-inclusion criteria are all incomplete registrations during the same period. 126 pregnant women were selected for this study.

To perform the vaginal samples, the patient goes to the laboratory without personal hygiene, suspend any antibiotic 48 hours rather, as well as sex 24 hours instead.

In the laboratory, the sample is made with three swabs; a swab is used to take the sample from the endocervix and two other swabs are used to take the sample from the vagina. One of the vaginal swabs is used to make fresh condition for looking for clues-cells, Trichomonas vaginalis, red and white blood cells, and 
yeasts.

Gram stain is made from the other vaginal swab and the endocard swab. The Gram stain makes it possible to look for Gram diplococci on the one hand intracellular and extracellular (gonococcal) negatives, and intracellular and extracellular Gram-variable coccobacilli (Gardnerella vaginalis), Gram-negative intracellular and extracellular Gram-negative bacilli (Mobiluncus spp.), grampositive bacilli of varying length (Bacillus Doderlein), Gram-positive, Corynebacterium-type bacilli, other bacteria (Gram-negative bacilli and Gram-positive cocci), and the presence of yeast and mycelial pseudo-filaments [10].

Smears were classified and interpreted according to the Nugent score [11] as shown in Table 1 and Table 2 respectively [12].

Seeding is systematic on Thayer Martin (TM) agar and Sabouraud chloramphenicol agar. Gram directs the choice of bromo-cresol-purple agar (BCP), nalidixic acid agar and Eosine Methylene Blue agar (EMB).

The media were incubated for 24 hours at $37^{\circ} \mathrm{C}$ and under $\mathrm{CO}_{2}$ for Thayer-Martin agar. On each medium, suspicious colonies were identified and their identification was carried out according to the classic bacteriological characters (catalase, appearance of colonies with a color shift of the media, metallic reflection) and by biochemical characters using mini-galleries (Kligler-Hajna, Simmons citrate, mannitol/mobility and urea/indole). The antibiotic susceptibility of the different strains isolated was determined by the standard antibiogram antimicrobial diffusion method on agar medium, according tothe recommendations of the antibiogram committee of the French Society of Microbiology [13] [14].

Table 1. Nugent's scoring of vaginal swabs (number based on average of 10 fields).

\begin{tabular}{cccccc}
\hline \multirow{2}{*}{ Morphotype } & \multicolumn{3}{c}{ Number of organisms per oil immersion field } \\
\cline { 2 - 5 } & None & $<1$ & $1-4$ & $5-30$ & $>30$ \\
\hline Lactobacillus species & 4 & 3 & 2 & 1 & 0 \\
Gardnerella \& anaerobic Gram-negative bacilli & 0 & 1 & 2 & 3 & 4 \\
Curved Gram-negative bacilli (Mobiluncus species) & 0 & 1 & 1 & 2 & 2 \\
\hline
\end{tabular}

Table 2. Interpretation of nugent's score.

\begin{tabular}{ccc}
\hline $\begin{array}{c}\text { Nugent's } \\
\text { score }\end{array}$ & And & Interpretation \\
\hline $0-3$ & No clue cells & Normal vaginal flora \\
$4-6$ & No clue cells & Intermediate or Not consistent with Bacterial vaginosis \\
$4-6$ & Clue cell present & Indicative of bacterial vaginosis \\
$\geq 7$ & Clue cell present or absent &
\end{tabular}


Statistical analyzes.

The statistical software SPSS version 22 for Windows and MedCal 13 were used for data processing and comparison of proportions. Chi-square was used and the statistical threshold was set at $P<0.05$.

\section{Result}

The retrospective analysis of the data identified a total of 126 pregnant women, who performed their consultation at the Department of Gynecology at Bè Hospital and their vaginal swabs in the microbiology laboratory of the same hospital.

The age group was 12 to 41 years old with an average age of 28.10 years. Their age distribution is shown in Table 3.

We recorded 62 women (49.21\%) with scanty leucorrhoea (Table 4). Of the women recruited, 90 (71.42\%) had an infection (Figure 1). Candida albicans was the most isolated with $47.97 \%$ followed by Gardnerella vaginalis (47.97\%); Trichomonas vaginalis was poorly recovered (4.06\%) (Table 5). The distribution of isolated organisms by age is shown in Table 6. Candida albicans is isolated in $6.5 \%$ of women aged 35 to 40, followed by Gardnerella vaginalis $4 \%$ and Trichomonas vaginalis $2 \%$. The 25 to 30 age group has the highest rate of isolation germ and is respectively 16\%, 14\%, 4\% and 1\% for Candida albicans, Gardnerella vaginalis, Mobiluncus spp. and Trichomonas vaginalis.

Strains of Candida albicans were $100 \%$ resistant to the following antifungals: miconazol, clotrimazol and econazol.

Table 3. Distribution of pregnant women by age.

\begin{tabular}{ccc}
\hline Age (years) & Effectif & Percentage \\
\hline$[10-15]$ & 1 & $0.79 \%$ \\
{$[15-20]$} & 5 & $3.97 \%$ \\
{$[20-25]$} & 25 & $19.84 \%$ \\
{$[25-30]$} & 46 & $36.51 \%$ \\
{$[30-35]$} & 31 & $24.60 \%$ \\
{$[35-40]$} & 16 & $12.70 \%$ \\
{$[40-45]$} & 2 & $1.59 \%$ \\
Total & 126 & $100 \%$ \\
\hline
\end{tabular}

Table 4. Classification of leucorrhoea abundance.

\begin{tabular}{ccc}
\hline Leucorrhoea abundance & Effectif & Percentage \\
\hline Scanty & 62 & $49.21 \%$ \\
Abundant & 47 & $37.30 \%$ \\
Very abundant & 17 & $13.49 \%$ \\
Total & 126 & $100 \%$ \\
\hline
\end{tabular}


Table 5. Distribution of microorganisms found.

\begin{tabular}{ccc}
\hline Microorganismes & Effectif & Percentage \\
\hline Trichomonas intestinalis & 5 & $4.06 \%$ \\
Candida spp. & 6 & $4.88 \%$ \\
Mobiluncus spp. & 6 & $4.88 \%$ \\
Gardnerella vaginalis & 47 & $38.21 \%$ \\
Candida albicans & 59 & $47.97 \%$ \\
Total & 123 & $100 \%$ \\
\hline
\end{tabular}

Table 6. Distribution of microorganisms by age group.

\begin{tabular}{ccccccccc}
\hline Age (years) & {$[\mathbf{1 0}-\mathbf{1 5}]$} & {$[\mathbf{1 5}-\mathbf{2 0}]$} & {$[\mathbf{2 0}-\mathbf{2 5}]$} & {$[\mathbf{2 5}-\mathbf{3 0}]$} & {$[\mathbf{3 0}-\mathbf{3 5}]$} & {$[\mathbf{3 5}-\mathbf{4 0}]$} & {$[\mathbf{4 0}-\mathbf{4 5}]$} & Total \\
\hline Candida albicans & 0 & $2(1.63 \%)$ & $13(10.57 \%)$ & $20(16.26 \%)$ & $16(13.00 \%)$ & $8(6.50 \%)$ & 0 & $59(47.96 \%)$ \\
Gardnerella vaginalis & 0 & 0 & $10(8.13 \%)$ & $18(14.63 \%)$ & $14(11.38 \%)$ & $5(4.07 \%)$ & 0 & $47(38.21 \%)$ \\
Mobiluncus spp. & 0 & 0 & $1(0.81 \%)$ & $5(4.07 \%)$ & 0 & 0 & 0 & $6(4.88 \%)$ \\
Candida spp. & 0 & 0 & $1(0.81 \%)$ & $2(1.63 \%)$ & $1(0.81 \%)$ & $2(1.63 \%)$ & 0 & $6(4.88 \%)$ \\
Trichomonas vaginalis & 0 & 0 & 0 & $2(1.63 \%)$ & 0 & $3(2.44 \%)$ & 0 & $5(4.07 \%)$ \\
$\quad$ Total & 0 & $2(1.63 \%)$ & $25(20.32 \%)$ & $47(38.22 \%)$ & $31(25.19 \%)$ & $18(14.64 \%)$ & 0 & $123(100 \%)$ \\
\hline
\end{tabular}

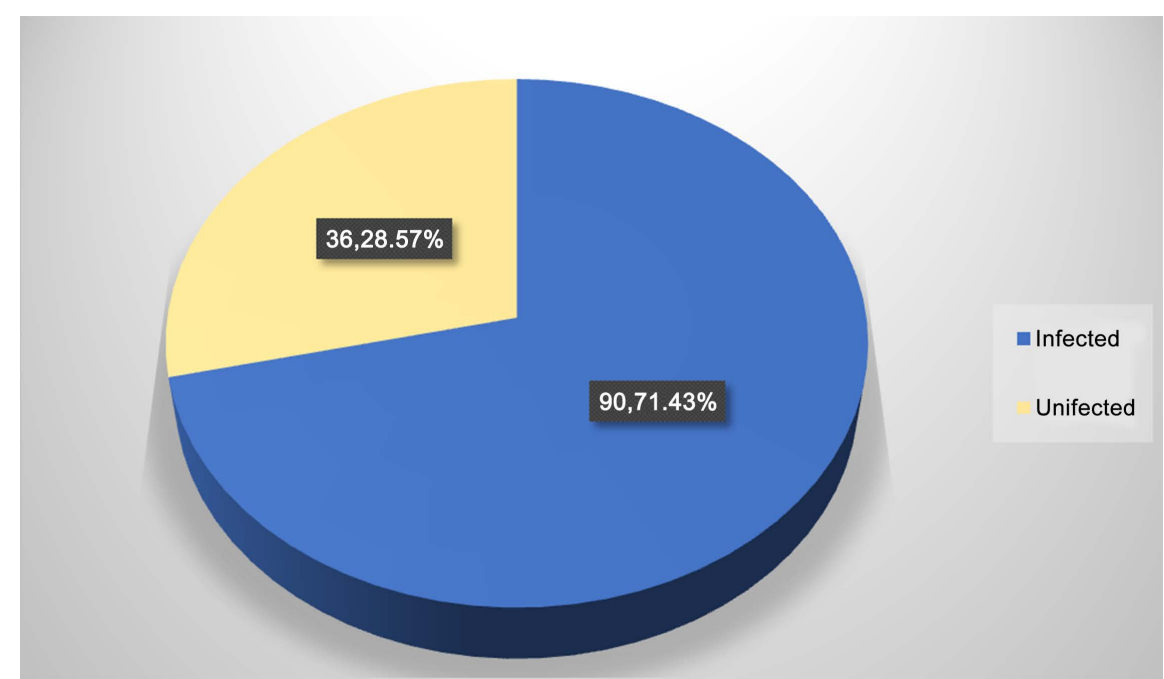

Figure 1. Prevalence of vaginal infection.

\section{Discussion}

In this study conducted between May 2008 and December 2013, we recorded 126 vaginal specimens in the Bè hospital, in pregnant women who met the criteria for inclusion and non-inclusion. Nadembega found 118 cases [15], which is in agreement with our data; however, other studies were performed with a larger sample size [9] [16] [17] [18] [19]. A large sample size would reflect the true proportions of the population conditions.

The age of the study population varies between 12 and 41 years, an average of 
28.10 years; this is an average close to that obtained in a similar study conducted by Tchelougou in the central region of Togo in 2011 [9].

The most exposed age group is between 20 and 35 years old; it is the age of procreation and during which the sexual activity is intense; this would explain this high rate. This is the most represented age group. Unlike us, Benchellal in 2011 found an age range of 25 to 53 years in Morocco [20] while Anane found 20 to 39 years in 2010 in Tunisia [21] which is close to our results.

Leucorrhoea is often abundant among women in our study in the maritime region of Togo; this result is similar to that of Tchelougou (45.37\%) in the central region of the country [9]; we noticed a significant difference depending on the character "scanty" (6.95\%) and "very abundant" (45.37\%). This difference can be explained by the social and cultural diversities and behaviors of populations [22] [23] [24] [25] that could affect their physiology.

The percentage of vaginal contamination observed in the study population is $71.42 \%$. These results confirm those obtained by Tchelougou [9] in 2011 in Sokodé $(73.18 \%)$.

Gardnerella vaginalis and Candida albicans account for most laboratory-identified germs ( $86.18 \%)$ during the study period; this result is similar to that of Tchelougou [9] in 2011 which is $86.08 \%$.

There is a high prevalence of Candida albicans (47.97\%) among pregnant women compared to the works of Tchelougou in 2011 in Sokodé [9]. Candida albicans can increase premature delivery rates and decrease neonatal birth weight [18], hence the need to follow women during pregnancy.

According to Benchellal, the risk factors involved in the occurrence of vulvovaginal candidiasis are: pregnancy, poor hygiene habits and frequent intimate toilet [20]. In fact, there is a marshy area, so that the water used by the population of Bè could be wet; This could also explain the high rate of vaginal infection in the area.

We found that Mobiluncusspp had a rate of $4.88 \%$; this result is not similar to that found by Tchelougou in 2011 [9]. Candida spp. represented 4.88\%; this result is similar to that of Cravello [26] in 2001, which reports that in mycotic vulvovaginitis, Candida albicans occupies 9 out of 10 cases, compared to 1 out of 10 cases for Candida spp. Trichomonas intestinalis (4.06\%) has a similar rate to that found in 2011 by Tchelougou (3.66\%) in the central region [9], unlike us Nadembega did not find Trichomonas intestinalis [15].

In this study, we noted that Candida albicans was resistant to miconazol, clotrimazol and econazol. This resistance could be explained by the use of unknown products for intimate toilets. This resistance is at the origin of the therapeutic failure. Nadembega gets results different from ours [15].

\section{Conclusion}

From the analysis of the retrospective study carried out between May 2008 and December 2013, it appears that the rate of vaginal infection is $71.42 \%$; Candida 
albicans and Gardnerella vaginalis were the most isolated respectively with a frequency of $47.97 \%$ and $38.21 \%$. The most exposed age group was 20 to 35 years old. All strains of Candida albicans isolated are resistant to Miconazol, Clotrimazol and Econazol. These preliminary results provide information on the prevalence of vaginal infections and on the susceptibility profile of isolated Candida albicans strains. However, it would be desirable to continue the studies over a much larger period and on a larger sample size for a better appreciation of the frequency of isolated organisms.

\section{References}

[1] Lamont, R.F., Sobel, J.D., Akins, R.A., Hassan, S.S., Chaiworapongsa, T., Kusanovic, J.P. and Romero, R. (2011) The Vaginal Microbiome: New Information about Genital Tract Flora Using Molecular Based Techniques. BJOG, 118, 533-549. https://doi.org/10.1111/j.1471-0528.2010.02840.x

[2] Lidbeck, A. and Nord, C.E. (1993) Lactobacilli and the Normal Human Anaerobic Microflora. Clinical Infectious Diseases, 16, S181-S187. https://doi.org/10.1093/clinids/16.Supplement_4.S181

[3] Balaka, B., Agbèrè, A., Dagnra, A., Baeta, S., Kessie, K. and Assimadi, K. (2005) Genital Bacterial Carriage during the Last Trimester of Pregnancy and Early/Onset Neonatal Sepsis. [Portage génital bactérien au dernier trimestre de la grossesse et infection néonatale précoce]. Archives de Pédiatrie, 12, 514-519. https://doi.org/10.1016/j.arcped.2005.02.010

[4] Ratner, A.J., Gilbert, N.M., Lewis, W.G. and Lewis, A.L. (2013) Clinical Features of Bacterial Vaginosis in a Murine Model of Vaginal Infection with Gardnerella vaginalis. PLoS ONE, 8, e59539. https://doi.org/10.1371/journal.pone.0059539

[5] Shetty, A.K. and Davis, B. (2012) Screening for Bacterial Vaginosis in Pregnant Women and Its Outcome on Pregnancy. International Journal of $A J$ Institute of Medical Sciences, 1, 20-25.

[6] Coleman, J.S., Gaydos, C.A. and Witter, F. (2013) Trichomonas vaginalis Vaginitis in Obstetrics and Gynecology Practice: New Concepts and Controversies. Obstetrical \& Gynecological Survey, 68, 43-50. https://doi.org/10.1097/OGX.0b013e318279fb7d

[7] Gülmezoglu, A.M. and Azhar, M. (2011) Interventions for Trichomoniasis in Pregnancy (Review). Cochrane Database of Systematic Reviews, No. 5, 16.

[8] da Silva, D.S. (2012) Bacterial Vaginosis in Portugal: Diagnosis of Gardnerella vaginalis and Atopobium vaginae in Healthy or Symptomatic Women. Citeseer.

[9] Tchelougou, D., Karou, D.S., Kpotsra, A., Balaka, A., Assih, M., Bamoke, M., et al. (2013) Vaginal Infections among Pregnant Women in the Regional Hospital Complex of Sokodé (Togo) between 2010 and 2011. [Infections vaginales chez les femmes enceintes au centre hospitalier régional de Sokodé (Togo) entre 2010 et 2011]. Médecine et Santé Tropicales, 23, 49-54.

[10] Winn, W. (2006) Aerobic and Facultative Gram Positive Bacilli. Koneman's Color Atlas and Text Book of Diagnostic Microbiology, 765-857.

[11] Nugent, R.P., Krohn, M.A. and Hillier, S.L. (1991) Reliability of Diagnosing Bacterial Vaginosis Is Improved by a Standardized Method of Gram Stain Interpretation. Journal of Clinical Microbiology, 29, 297-301.

[12] Udayalaxmi, B.G., Kotigadde, S. and Shenoy, S. (2011) Comparison of the Methods 
of Diagnosis of Bacterial Vaginosis. Journal of Clinical and Diagnostic Research, 5, 498-501.

[13] Bonnet, R., Caron, F., Cavallo, J., Chardon, H., Chidiac, C., Courvalin, P., et al. (2013) Antibiogram Committee of the French Microbiology Society. Recommendations.

[14] Paugam, A. (2005) Antifongigram: Techniques and Interpretation. [Antifongigramme: Techniques et interprétation]. BioTribune Magazine, 16, 25.

[15] Nadembega, C.W., Djigma, F., Ouermi, D., Karou, S.D. and Simpore, J. (2017) Prevalence of Vaginal Infection in 15 to 24 Years Women in Ouagadougou, Burkina Faso. Journal of Applied Pharmaceutical Science, 7, 209-213. https://doi.org/10.7324/JAPS.2017.70131

[16] Saleem, F., Malik, M., Shahid, M. and Tayyab, M. (2017) Bacterial Vaginosis; Comparison between Metronidazole Vaginal Gel and Clindamycin Vaginal Cream for Treatment of Bacterial Vaginosis. Professional Medical Journal, 24, 252-257. https://doi.org/10.17957/TPMJ/17.3668

[17] Rathod, S.D., Klausner, J.D., Krupp, K., Reingold, A.L. and Madhivanan, P. (2012) Epidemiologic Features of Vulvovaginal Candidiasis among Reproductive-Age Women in India. Infectious Diseases in Obstetrics and Gynecology, 2012, Article ID: 859071. https://doi.org/10.1155/2012/859071

[18] Holzer, I., Farr, A., Kiss, H., Hagmann, M. and Petricevic, L. (2017) The Colonization with Candida Species Is More Harmful in the Second Trimester of Pregnancy. Archives of Gynecology and Obstetrics, 295, 891-895.

https://doi.org/10.1007/s00404-017-4331-y

[19] Lopes, P.H.S., Pacini, V.L. and Norberg, A.N. (2017) Genital Infection by Gardnerella vaginalis and Candida spp. among Women in Nova Iguaçu City, Rio de Janeiro Province, Brazil. Open Access Library Journal, 4, 1-7.

[20] Benchellal, M., Guelzim, K., Lemkhente, Z., Jamili, H., Dehainy, M., Moussaoui, D.R., Lmimouni, B., et al. (2011) Vulvovaginal Candidiasis in the Military Teaching Hospital Mohammed V (Morocco). Journal of Medical Mycology, 21, 106-112. https://doi.org/10.1016/j.mycmed.2011.03.003

[21] Anane, S., Kaouech, E., Zouari, B., Belhadj, S., Kallel, K. and Chaker, E. (2010) Vulvovaginal Candidiasis: Risk Factors and Clinical and Mycological Characteristics. Journal of Medical Mycology, 20, 36-41. https://doi.org/10.1016/j.mycmed.2010.01.001

[22] Akpavi, S., Chango, A., Tozo, K., Amouzou, K.S., Batawila, K., Wala, K., Dantsey-Barry, H., et al. (2008) Nutrition/Health Value of Some Minor Food Leguminous Plant Species in Togo. Acta Botanica Gallica, 155, 403-414. https://doi.org/10.1080/12538078.2008.10516120

[23] Batawila, K., Akpavi, S., Wala, K. and Kanda, M. (2005) Diversity and Management of Gathering Vegetable in Togo. Developing African Leafy Vegetables for Improved Nutrition, 55.

[24] Faist, T. (2010) Cultural Diversity and Social Inequalities. Social Research: An International Quarterly, 77, 297-324.

[25] Fearon, J.D. (2003) Ethnic and Cultural Diversity by Country. Journal of Economic Growth, 8, 195-222. https://doi.org/10.1023/A:1024419522867

[26] Cravello, L. (2001) Vaginal Infections of Woman. Leucorrhoea. La revue du praticien, 51, 2255-2261. 